\title{
The Effects of Spread Spectrum Techniques in Mitigating Conducted EMI to LED Luminance
}

\author{
Mohammad Yanuar Hariyawan ${ }^{*, *}$, Risanuri Hidayat*, and Eka Firmansyah* \\ * Department of Electrical Engineering and Information Technology, Universitas Gadjah Mada \\ *** Department of Electrical Engineering, Politeknik Caltex Riau
}

\begin{tabular}{l}
\hline \hline Article Info \\
\hline Article history: \\
Received Nov 30, 2015 \\
Revised Mar 7, 2016 \\
Accepted Mar 21, 2016 \\
\hline
\end{tabular}

Keyword:

EMI

LED driver

spread spectrum

mitigate

\begin{abstract}
Rapid voltage and current changes in recently ubiquitous LED driver have a potency to interfere other devices. Some solutions with special converter design, component design, EMI filter, and spread-spectrum techniques have been proposed. Due to cost-size-weight constraints, the spread-spectrum technique seems to be a potential candidate in alleviating EMI problem in LED application. In this paper, the effectiveness of conducted EMI suppression performance of the spread-spectrum technique is evaluated. Spread spectrum techniques applied by giving disturbance to the LED driver system with three profile signals, filtered square, triangular, and sine disturbance signal to the switching pattern of a buck LED driver topology. From the experiment results, $472.5 \mathrm{kHz}$ triangular and $525 \mathrm{kHz}$ sine signal can reduce EMI by $42 \mathrm{~dB}$ while the filtered square signal can reduce EMI $40.70 \mathrm{~dB}$ compared to fundamental constant-frequency reference $669 \mathrm{kHz}$. The filtered square signal can reduce the average power level better than other signal disturbance of $5.852618 \mathrm{~dB} \mu \mathrm{V}$. LED luminance decreases when the spread-spectrum technique is applied to the system.
\end{abstract}

Copyright (c) 2016 Institute of Advanced Engineering and Science. All rights reserved.

Corresponding Author:

Mohammad Yanuar Hariyawan

Department of Electrical Engineering and Information Technology, Universitas Gadjah Mada

Jalan Grafika No. 2, Yogyakarta, 55281 Indonesia

$+62811760655$

yanuar@pcr.ac.id

\section{INTRODUCTION}

Nowadays, light emitting diodes (LEDs) are becoming increasingly popular use in various applications, such as indoor and outdoor lighting, street lighting, decorations, and vehicle applications. The main purpose of LED lights is energy saving due to the use of low power, high efficiency and low maintenance [1]-[4]. In addition, it is durable, environmentally friendly, and no toxic substances composition compared to other lighting types [5]-[10]. To achieve high efficiency in energy transfer, switched-mode power supply (SMPS) topology is applied, such as buck, boost, flyback, cuk dan buck-boost [11]-[22]. In addition, the SMPS is widely applied due to the benefits offered in terms of size, weight, cost and performance. SMPS is usually implemented using pulse width modulation (PWM). PWM operates at a constant frequency. The weakness of this system is the fundamental and harmonic frequencies emitted through conducted and radiated mechanism. This emission is called electromagnetic interference (EMI). As a result, the potential converter does not meet the standards of electromagnetic compatibility (EMC) [11],[14][23],[24].

SMPS has a periodic switching pattern, i.e. EMI spectrum which consists of the fundamental and harmonic frequencies with significant amplitudes up to the 20th harmonic [25]. This condition could probably pass the limit set by the conducted EMI CISPR 22 Class B standards. Some solutions are used to reduce EMI issues in LED drivers, including the converter designs [12],[19],[18],[22],[26]-[32], components design [17],[33]-[35], EMI filter [30],[36] and spread-spectrum techniques [6], [11], [14], [23], [37]-[39]. Of all these solutions, the spread-spectrum technique is a solution that is inexpensive and efficient in mitigating EMI.

In this paper, conducted EMI mitigation is done by applying a spread-spectrum techniques in buck topology LED driver and observing its effect on the LED luminance. Spread spectrum techniques implemented by giving disturbance to the system with 3 profile of waveform signals, filtered square, triangle and sinusoidal waveform signals. 
Effectiveness in mitigating the effects of the conducted EMI and LED luminance will be studied. This will ensure electromagnetic compatibility (EMC) of the system.

\section{CONDUCTED EMI MITIGATION IN LED DRIVER}

All the LED driver have to comply with radiation emission, IEC/EN 61000-6-3 standards, which limits in the $150 \mathrm{kHz}$ to $30 \mathrm{MHz}$ frequency range. This Standard uses the limits specified by CISPR 22 in the USA and the European Norm EN55022. Limits given in CISPR 22 and EN55022 standard are intended for devices related to computers and communications, but this has been adopted as a common limit for all electronic products, including the lighting. CISPR 22 standard for conducted emissions shown in Figure 1.

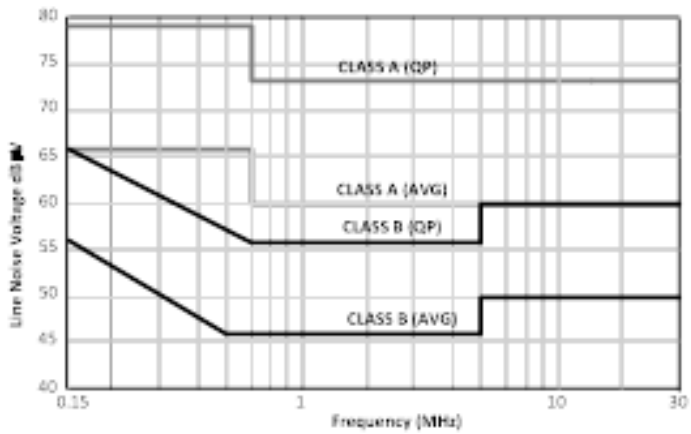

Figure 1. Conducted Emission CISPR 22 Standard

One method to reduce the amplitude of the EMI is to use a variable switching frequency, which is known as spread-spectrum techniques [40]. In this case, the switching converter is not working at a fixed frequency. Frequency will vary within a small range, up and down of the value of the base, it will provide a wider spectrum with a lower amplitude. It is intended to spread a centralized energy into the frequency band, as shown in Figure 2.

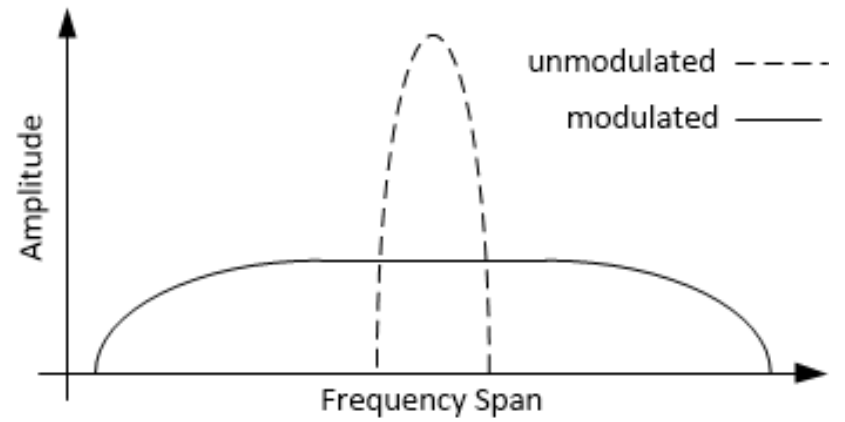

Figure 2. Representation of Signal Clock Frequency with and without Spread-Spectrum Modulation

Spread spectrum technique is used in many applications, class D amplifier [5], [6], the microprocessor clock generator [7]-[9], electronic ballasts [10] and on the LCD display panel [11]. Spread spectrum technique is also adopted in communication protocols such as serial ATA [12]. In the dc/dc switching converter, this technique has been widely studied since 1994 [13] emissions in the common mode and differential mode, both of which can be reduced with frequency modulation.

The research that addresses EMI mitigation techniques in LED driver using spread-spectrum method was first proposed in 2008 [37]. In this study, Gated PWM (GPWM) proposed, distributed switching pulses resulting in lower EMI than the linear PWM. GPWM take advantage of the binary PWM (BPWM): data flow control and the required low amount of buffer memory in processing and storage. LED dimming technique, GPWM recomended for LED video display where it takes a high-level grayscale. This technique offers improved gray level compared with PWM and BPWM.

Frequency jitter technique, proposed to solve EMI problems in PWM dimming LED driver module [6]. PWM dimming circuit consists of a selector and comparator. To spread the switching frequency in a specific band, blocks of frequency jittering are used. Reference voltage in large numbers is needed to obtain different frequencies from which each frequency will represent specific value. Simple resistance divider is used to obtain different reference 
voltages. A technique known as spread-spectrum frequency modulation (SSFM) is proposed to mitigate EMI [11]. In this technique, the switching frequency will swing in a narrow range, up and down of the fundamental frequency. This technique produces a wider spectrum with a lower amplitude. Operating frequency will be stretched up to $\pm 2 \sim 4 \%$ up and down of the fundamental frequency. Frequency can not be varied too much, because it will affect the average current through the LED.

Active EMI mitigation scheme using pseudorandom frequency modulation is proposed to minimize EMI [14]. It is different from most of the techniques that use DSP or MCU, the proposed mitigation technique uses $10^{t h}$ order linear feedback shift register (LFSR) to generate pseudo-random vectors that are used to control the PWM, which four out of ten bits of LFSR is used to control the PWM. In-depth analysis has been carried out and showed promising results. $0.35 \mu \mathrm{m}$ system is designed in TSMC CMOS process and meet EMI standards for LED driver without sacrificing stability and efficiency. The measurement results show that the proposed timing can reduce EMI by $14 \mathrm{~dB}$ while maintaining a constant current of $120 \mathrm{~mA}$.

Probabilistic PWM (PPWM) pulse generation using modified linear feedback shift register (LFSR) is proposed to address EMI [38]. The emergence frequency, peak value, and variety of incoming currents can be reduced by PPWM control, which is stochastic choose PWM pulse timing and control LEDs connected serially, can effectively eliminate the problem of temperature and EMI. The test results showed that PPWM dimming can reduce the average value of the peak inflows of up to $2-5 \%$ and a variation of up to $35 \%$, with the cost of the hardware that is affordable.

Chaos-based pulse width modulation (CPWM) is used to suppress harmonics in the half-bridge resonant (HBR) LED drivers [23]. CPWM proposed to suppress EMI in high-power LED driver. CPWM circuit is used to generate chaos analog circuits by adopting Chua oscillator. By using an external chaotic signal to the PWM control circuit in the power supply half-bridge resonant (HBR) can effectively suppress EMI. The most substantial reduction of EMI by $24 \mathrm{~dB}$, is obtained when using a switching frequency of $565.56 \mathrm{kHz}$ at R14 $=100 \mathrm{k} \Omega$.

\section{RESEARCH METHOD}

The core of the experimental setup is the LM3409 LED driver demonstration board buck topology. The evaluation board provides interference to the switching system. The evaluation board is designed to drive 4 LEDs $(\mathrm{VO}=15 \mathrm{~V})$ at average maximum current LED (ILED=1A) of the DC input voltage (VIN=24V). Switching frequency $(\mathrm{FSW}=525 \mathrm{kHz}$ ) is the frequency to be achieved for the nominal point of operation, though FSW varies throughout the operating range. LM3409 demonstration board schematic converter shown in Figure 3, can accept input voltages with range $6 \mathrm{~V}$ to $42 \mathrm{~V}$. If the input voltage drop below the LED string voltage, converter drop out and ideally $\mathrm{VO}=$ VIN.

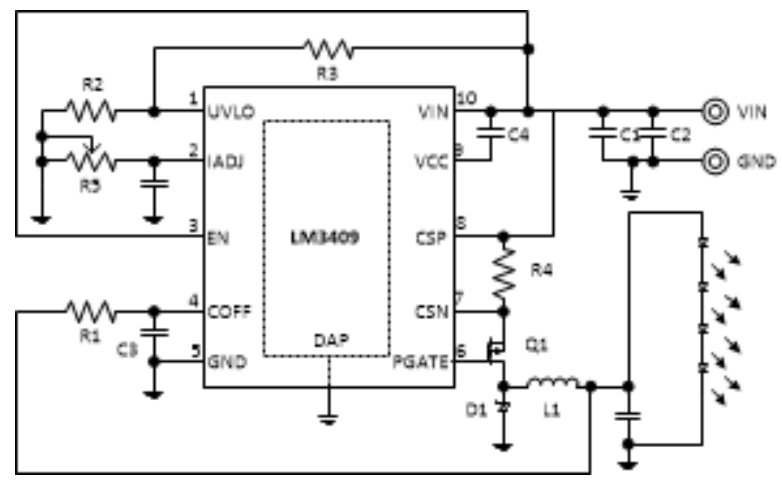

Figure 3. Schematic LM3409 LED Driver Buck Converter Evaluation Board

Two variations on the LED driver system testing was conducted to observe effectiveness of the system in reducing EMI, the LED driver in normal operation and LED driver with three wave forms as signal disturbance as shown in Figure 4. Converter set up testing is done using standard CISPR 22. Measurements were performed in 125 $\mathrm{kHz}-925 \mathrm{kHz}$ frequency range. The purpose of this arrangement is to create a test environment that is uniform to clarify the effect of the method chosen. By using the method and arrangement, it is expected the difference between a constant switching frequency and spreading switching frequency can be distinguished easily. 


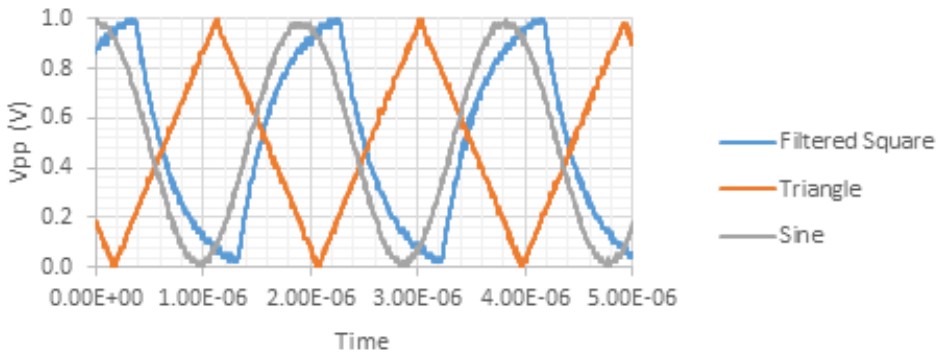

Figure 4. Three Profiles Signal Interference

\subsection{Constant-Frequency Reference Converter}

The experimental setup is carried out under normal conditions without any disturbance on IADJ pin with an input voltage of 24 volts. In the IC LM3409, there is IADJ pin connected to R5 potentiometer (250 K $\Omega$ ) (Figure $3)$. IADJ pin has function to adjust the brightness of LED lights by providing output voltage and current variations. Block diagram of the test can be seen in Figure 5. The parameters measured in this test is a spectrum EMI and LED luminance changes, when IADJ change from $0.01 \mathrm{~V}$ to $1.2 \mathrm{~V}$.

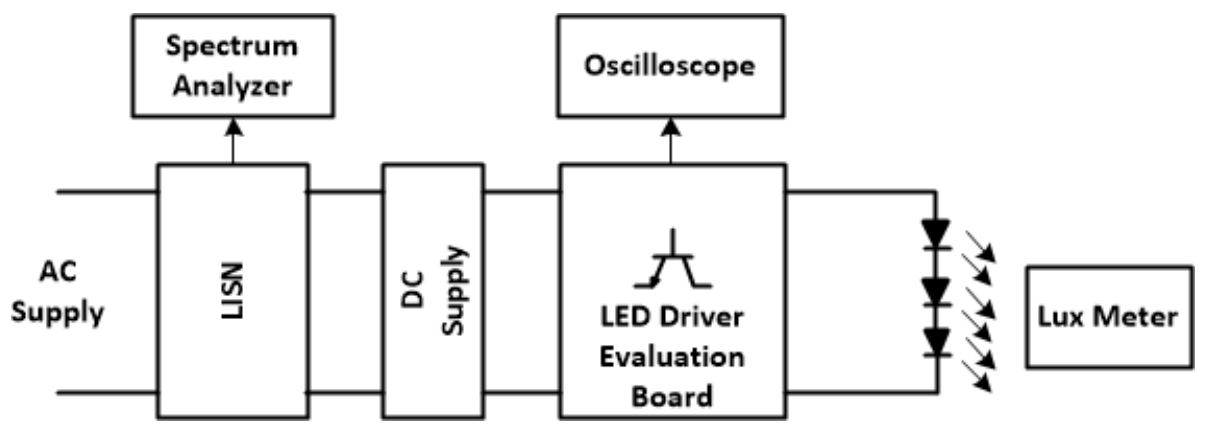

Figure 5. Block Diagram of Performance Testing Constant-Frequency Reference LED Driver

\subsection{LED Driver Performance Test by Feeding Disturbance to IADC Test Point}

This experiment step is done with the conditions providing disturbances in IADJ pin when R5 potentiometer set in minimum conditions value. These disturbance signals comes in three types of waveform, sine, filtered square, and the triangle that generates by function generator. Disturbance waveform signal has a voltage of $0-1 \mathrm{Vpp}$ with the frequency of $\pm 10 \%$ of the working frequency of $525 \mathrm{kHz}$ LED driver. The signal frequency will be set in $472.5 \mathrm{kHz}$, $498.75 \mathrm{kHz}, 525 \mathrm{kHz}, 551.25 \mathrm{kHz}$ and $577.5 \mathrm{kHz}$. Block diagram of the current testing system is given in the form of three waveform disturbance signals can be seen in Figure 6.

\section{RESULT AND ANALYSIS}

\subsection{LED Driver Performance Test in Constant-Frequency Reference}

The EMI generated on every change in the value of IADJ can be seen in Figure 7, it can be seen that when R5 value change, IADJ voltage and working frequency also changes. When compared with the CISPR 22 Class B, the level of power generated at each operating frequency exceeding the limit set by CISPR 22 Class B. The average power levels generated for all amplitude value is about $39.834 \mathrm{~dB} \mu \mathrm{V}$. In the $563 \mathrm{kHz}-683 \mathrm{KHz}$ frequency range, generated power levels above the maximum value set by CISPR. The highest power level exceeds the standard, occurs when the test point IADJ given voltage $0.2 \mathrm{Vpp}$ at a frequency of $627 \mathrm{KHz}$. When compared to standard CISPR having a difference of $15.9 \mathrm{~dB} \mu \mathrm{V}$.

When IADJ pin given different input voltages, LED luminance will change, can be seen in Figure 8 . The LED luminance will increase when IADJ changed from $0.023 \mathrm{mV}$ to $849 \mathrm{mV}$, after which the $849 \mathrm{mV}$ to $1200 \mathrm{mV}$ decreased LED luminance . 


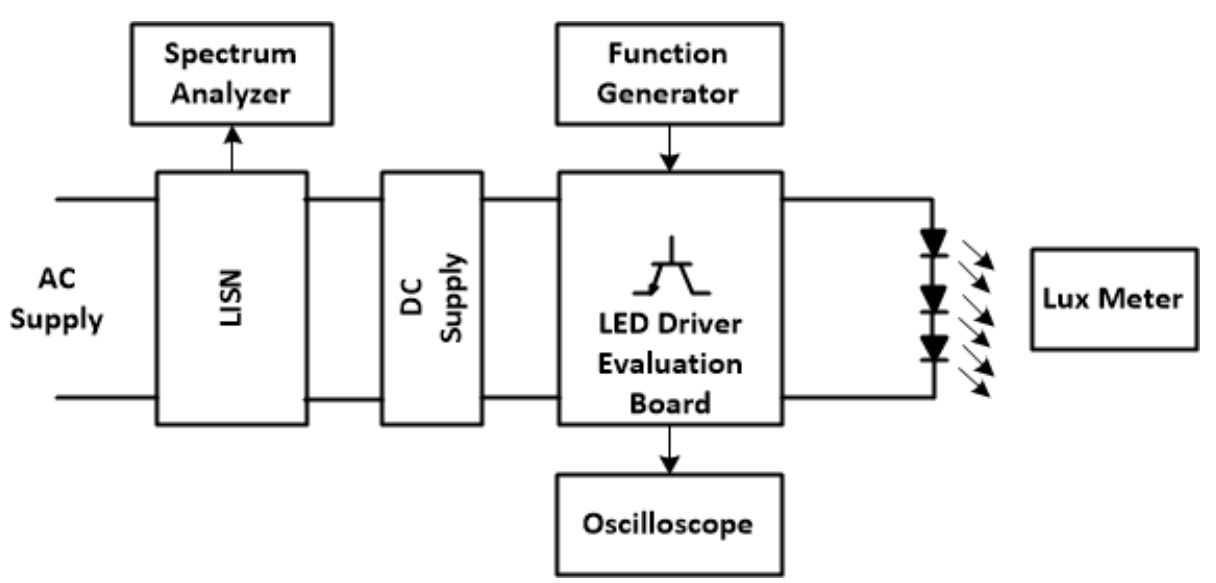

Figure 6. Block Diagram of Performance Testing LED Driver by Giving Disturbance to IADJ

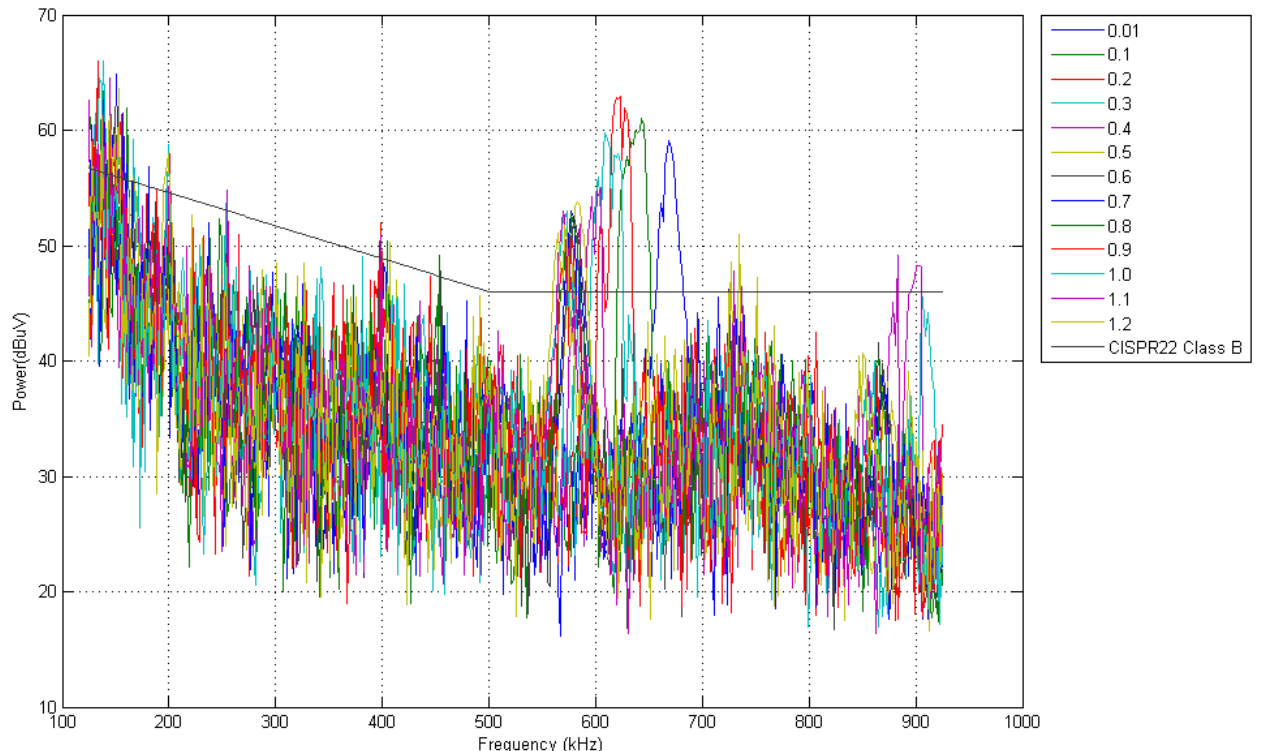

Figure 7. LED Luminance Vs IADJ

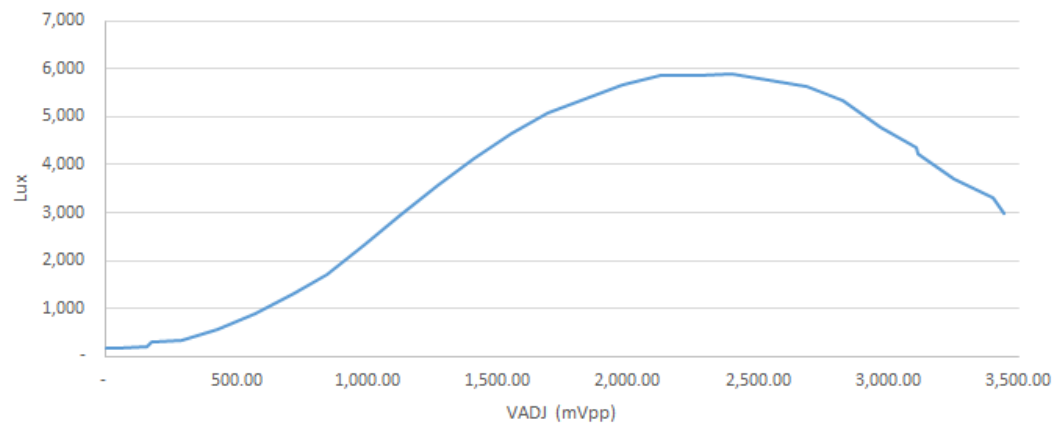

Figure 8. LED Luminance Vs IADJ

\subsection{LED Driver Performance by Feeding Disturbance on IADJ}

\subsubsection{Filtered Square Profile Signal Disturbance}

When given filtered square profile signal disturbance on the IADJ pin, the signal level is obtained as shown in Figure 9. In the frequency range from $563 \mathrm{kHz}-683 \mathrm{kHz}$, there is a decrease in por level when given filtered IJECE Vol. 6, No. 3, June 2016: 1332 - 1343 
square signal disturbance on IADJ pin. The average power level generated by the five frequency is about $28.6 \mathrm{~dB} \mu \mathrm{V}$. When compared with the power level of the reference signal power level there is a reduction about $5.8 \mathrm{~dB} \mu \mathrm{V}$. The most significant reduction of power level occurs at $525 \mathrm{kHz}$, its about $41.90 \mathrm{~dB}$, this value is quite significant if compared with previous research [14],[23]. The overall level of power generated by the filtered square signal below the established standards CISPR 22 Class B. Meanwhile the luminance produced by the LED when given the disruption of filtered square waveform is about 146 lux. The switching frequency varies between $292-675 \mathrm{kHz}$ as shown in Figure 10.

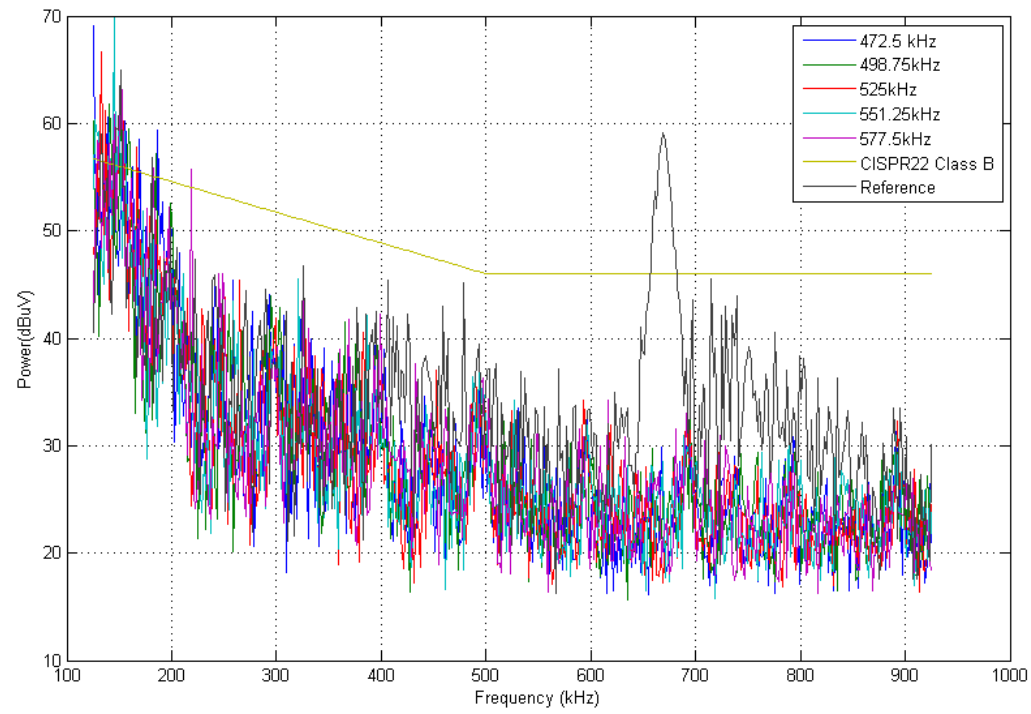

Figure 9. Power Levels Distribution when Given Filtered Square Signal Disturbance

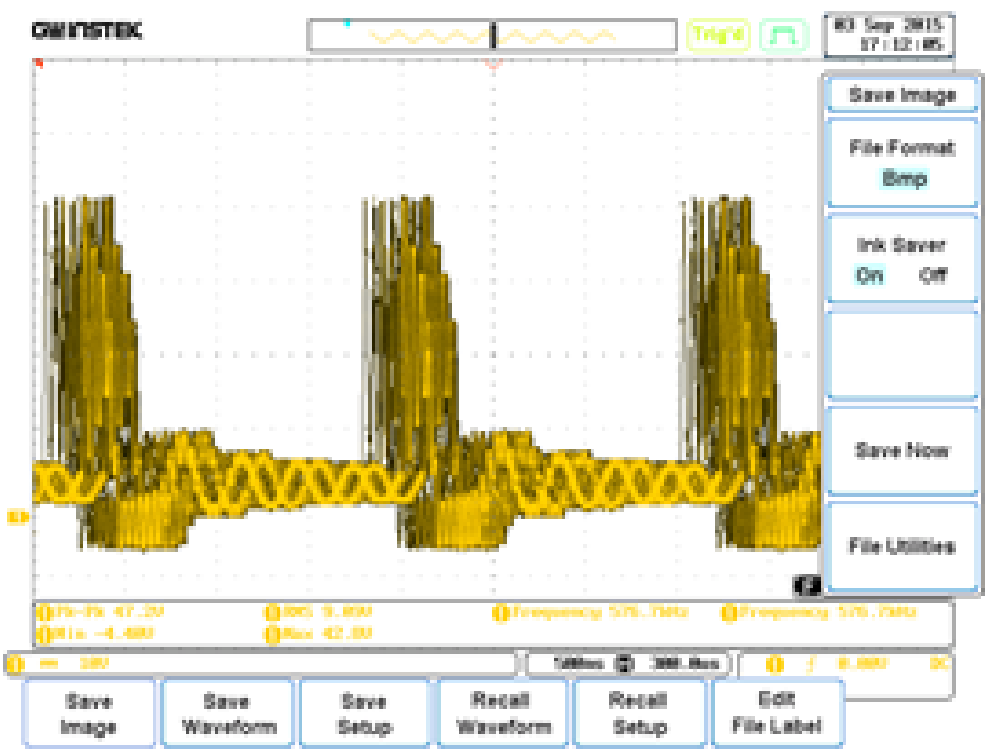

Figure 10. Switching Frequency when Given Filtered Square Signal Disturbance

\subsubsection{Triangle Wave Signal Disturbance}

When given triangular waveform with frequency range of $563 \mathrm{kHz}-683 \mathrm{kHz}$ at IADJ point there is power level reduction as shown in Figure 11. The average power level generated by the five frequency is about $29.6 \mathrm{~dB} \mu \mathrm{V}$. 
When compared with the power level of the reference power level signal there is a decrease of $4.8 \mathrm{~dB} \mu \mathrm{V}$. The most significant reduction of power level occurs when system is given $498.75 \mathrm{kHz}$ triangle signal, its about $40.60 \mathrm{~dB}$ this value is also quite significant if compared with previous research [14],[23]. As is the case when the system is given a filtered square waveform, the overall level of power generated by triangular waveform resulting disturbance levels below established standards CISPR 22 Class B. Whereas the luminance produced by the LED current when given triangular waveform is about 146 lux. The switching frequency varies between 281-683 kHz as shown in Figure 12 .

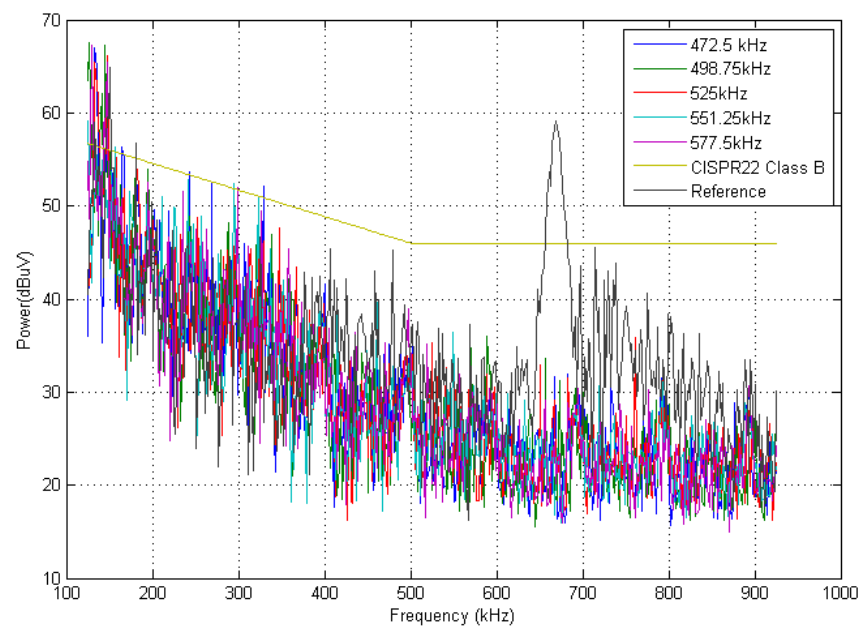

Figure 11. Power Levels Distribution when Given Triangle Signal Disturbance

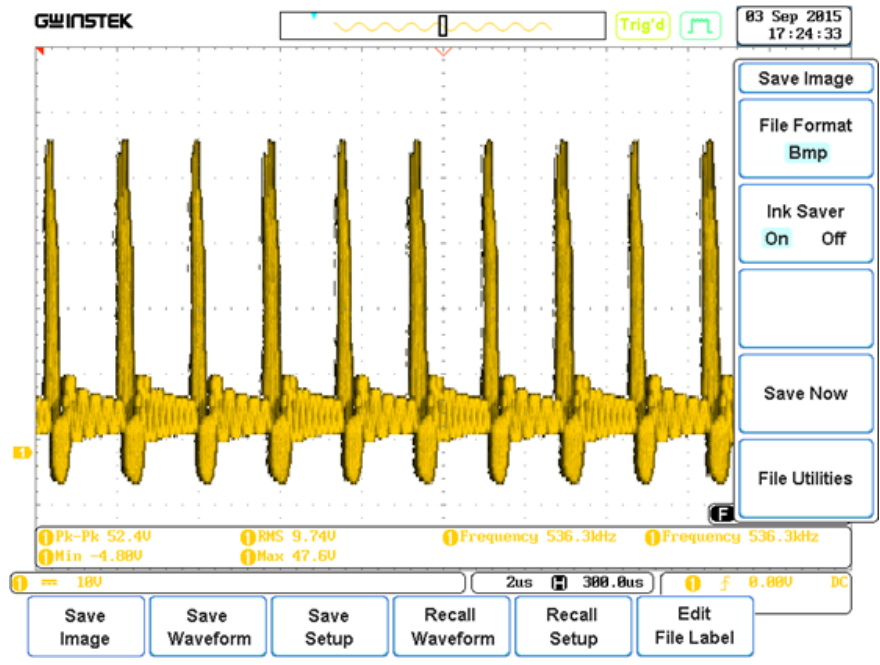

Figure 12. Switching Frequency when Given Triangle Signal Disturbance

\subsubsection{Sine Wave Signal Disturbance}

When given sine waveform disturbances on IADJ point as shown in Figure 14, in the $563 \mathrm{kHz}-683 \mathrm{kHz}$ frequency range, there is a decrease in power level. The average power level generated by the five frequency is about $29.5 \mathrm{~dB} \mu \mathrm{V}$. When compared with the power level reference signal there is a decrease in the power level about 4.9 $\mathrm{dB} \mu \mathrm{V}$. The most significant reduction of power level occurs when the frequency of $525 \mathrm{kHz}$, is about $42 \mathrm{~dB}$, this value is also quite significant if compared with previous research [14],[23]. As is the case when the system is given a signal disturbance filtered square and triangles waveform, the overall level of power generated by the sine waveform, the resulting disturbance levels below established standards CISPR 22 Class B. Whereas the luminance produced by the 
LED current is given filtered square waveform is about 139 lux. The switching frequency varies between $290-657 \mathrm{kHz}$ as shown in Figure 13.

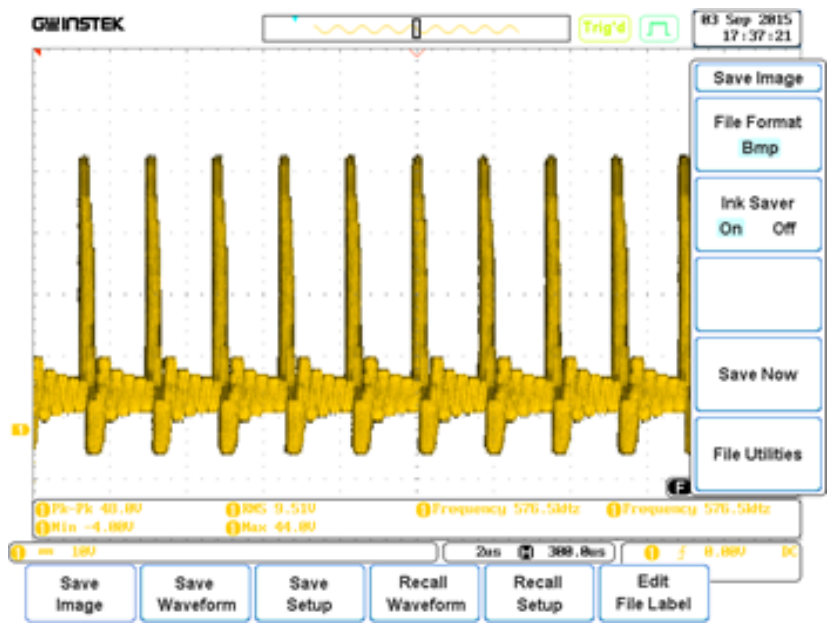

Figure 13. Switching Frequency when Given Sine Signal Disturbance

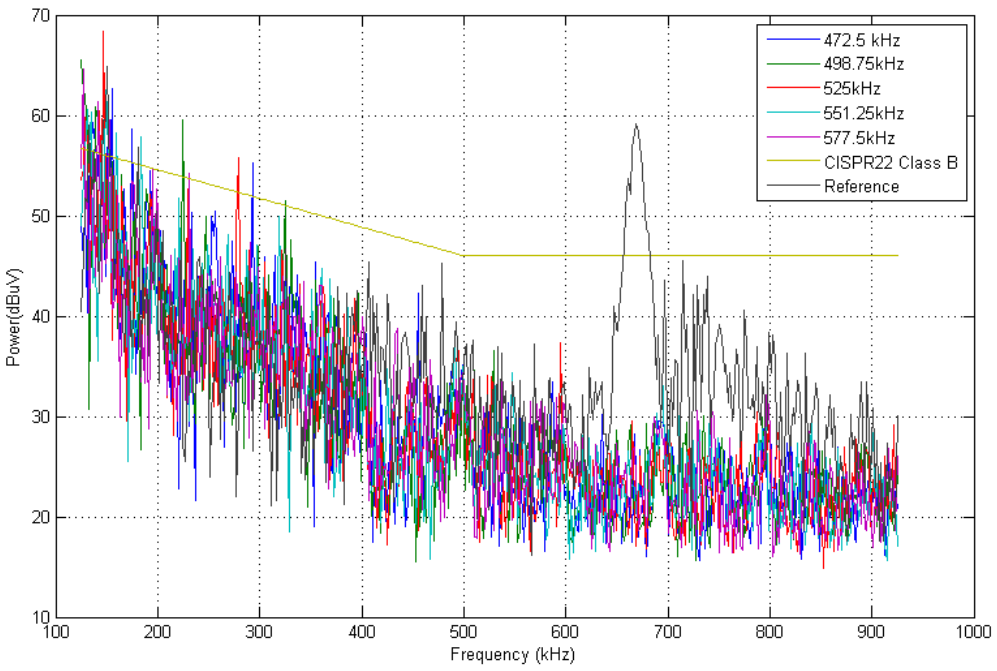

Figure 14. Power Levels when Given Sine Signal Disturbance

When the system is given three periodic waveforms at the point IADJ with a frequency of $525 \mathrm{kHz}$ and compared with a reference signal when the minimum dimming, filtered square has a better performance when compared with other waveform to suppress EMI, as shown in Figure 15. The average level of the power generated by the third signal is equal to $29.26143 \mathrm{~dB} \mu \mathrm{V}$. The average power level of squared filtered waveform has the smallest value when compared with others waveform is about $28.56309 \mathrm{~dB} \mu \mathrm{V}$. The average reduction power level of the third signal at $5.154281 \mathrm{~dB} \mu \mathrm{V}$, and filtered square waveform have better power level reduction is about $5.852618 \mathrm{~dB} \mu \mathrm{V}$. V. The average power level reduction of the third signal at $5.154281 \mathrm{~dB} \mu \mathrm{V}$, and filtered square waveform have better power level reduction is about $5.852618 \mathrm{~dB} \mu \mathrm{V}$. The most significant reduction of power level occurs when system given 525 $\mathrm{kHz}$ triangle disturbance, is about $42 \mathrm{~dB}$ reduction, this value is quite significant if compared with previous research [14],[23] which use non-periodic signal to mitigate EMI. Measurement results showed that the proposed mitigation scheme using $10^{\text {th }}$ order LFSR to generate pseudo-random vectors can reduce EMI only $14 \mathrm{~dB}$ [14]. CPWM which adopt Chua oscillator to generate chaotic signal can reduce EMI only $24 \mathrm{~dB}$ [23].

When the pin VDJ given disturbance, LED luminance decreases compared with LED driver works in constantfrequency reference. When the system works on a constant-frequency reference with a voltage of 0.07 to $1,129 \mathrm{mVpp}$, 
lux varies between 178-2,960 lux, as in Figure 8. LED luminance decrease significantly, less than about 2814 lux.As filtered square and traingle disturbance signal given at LED driver,luminance LED system is about 146 lux. whereas sinusoidal signals produce luminance 139 lux, as shown in Figure 16.

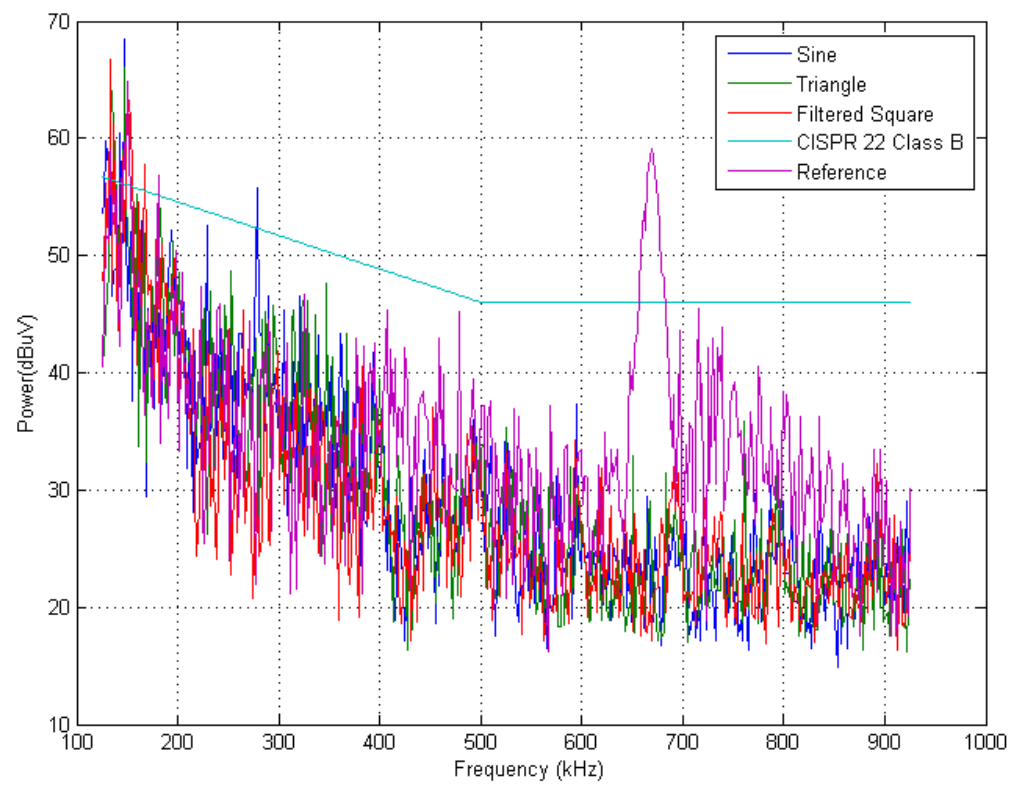

Figure 15. Comparison of Power Level Distribution 3 Different Signals Disturbance at $525 \mathrm{kHz}$

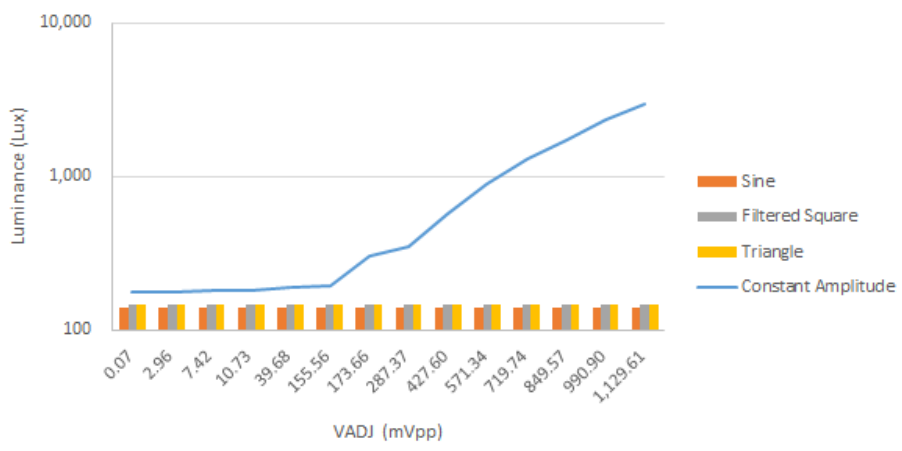

Figure 16. LED Luminance when Given Disturbance

\section{CONCLUSION}

The experiment results confirms that the spread-spectrum technique is effective in mitigating conducted EMI generated by the LED driver but sacrificing LED luminance. The results show that when the system is given filtered square, triangular and sine waveform disturbance signal can mitigate EMI generated by the LED driver. From the test results, $525 \mathrm{kHz}$ sine signal is the most efficient signal disturbance to mitigate EMI by $42 \mathrm{~dB}$ then followed by filtered square signal that can mitigate EMI by $41.9 \mathrm{~dB}$. The lowest average power level is achieved by filtered square signal is about $36.447 \mathrm{~dB} \mu$. The filtered square signal most significant can reduce the average power level about $3.27 \mathrm{~dB} \mu \mathrm{V}$. By providing three types of signal disturbance on the LED driver system resulting in decreased levels of LED luminance.

\section{REFERENCES}

[1] A. D. N. Ndokaj, A. , "LED Power Supply and EMC Compliance," Energy Conference and Exhibition (ENERGYCON), 2012 IEEE International, 2012, pp. 254 - 258 
[2] W. R. Ryckaert, K. A. G. Smet, I. A. A. Roelandts, M. Van Gils, and P. Hanselaer, 'Linear LED Tubes Versus Fluorescent Lamps: An Evaluation," Energy and Buildings, vol. 49, pp. 429-436, 2012.

[3] I. L. Azevedo, M. G. Morgan, and F. Morgan, "The Transition to Solid-State Lighting," Proceedings of the IEEE, vol. 97, pp. 481-510, 2009.

[4] M. S. Shur and A. Zukauskas, "Solid-State Lighting: Toward Superior Illumination," Proceedings of the IEEE, vol. 93, pp. 1691-1703, 2005.

[5] C. Qi, C. Quan, and L. Xiaobing, "Fast Estimation of LED's Accelerated Lifetime by Online Test Method," Electronic Components and Technology Conference (ECTC), 2014 IEEE 64th, 2014, pp. 1992-1995.

[6] Z. J. H. Z. L. Shengqian, "System Level Design of A LED Lighting Driver Based on Switching Power Supply," Microelectronics \& Electronics, 2009. PrimeAsia 2009. Asia Pacific Conference on Postgraduate Research in 2009, pp. $309-312$

[7] S. P. Y. C.-W. T. B.-J. Huang, "Charaterizing LEDs for Mixture of Colored LED Light Sources," in Electronic Materials and Packaging,'EMAP 2006. International Conference on Kowloon, 2006, pp. 1-5.

[8] S.-C. H. L.-L. L. M.-S. J. Y.-C. Hsieh, ” Assessment of Energy-Efficient LED Street Lighting Through Large-Scale Demonstration," Renewable Energy Research and Applications (ICRERA), 2012, pp. 1 - 5

[9] C. P. X. L. P. Z. L. X. X. Liu, ”RGB High Brightness LED Modules for Projection Display Application ”Journal Display Technology, vol. 7, pp. 448 - 453, 2011.

[10] T.-F. C. Wu, C.-C. ; Wu, C.-Y. ; Lu, P.-C. ; Chen, Y.-R., "Sequential Color LED Backlight Driving System for LCD Panels with Area Control," Power Electronics Specialists Conference, PESC 2007, Orlando, FL 2007, pp. 2947 - 2952

[11] L. Dong, Y. Ye, and L. He, ”A Novel PWM Controller IC for LED Driver with Frequency Spread,"Power and Energy Engineering Conference (APPEEC), 2010 Asia-Pacific, 2010, pp. 1-4.

[12] D. G. Lamar, J. Sebastian, M. Arias, and M. M. Hernando, "A Low-Cost AC-DC High-Brightness LED Driver with Power Factor Correction Based on Standard Peak-Current Mode Integrated Controllers," Energy Conversion Congress and Exposition (ECCE), 2010 IEEE, 2010, pp. 463-470.

[13] P. Athalye, M. Harris, and G. Negley, "A Two-Stage LED Driver for High-Performance High-Voltage LED Fixtures," Applied Power Electronics Conference and Exposition (APEC), 2012 Twenty-Seventh Annual IEEE, 2012, pp. 2385-2391.

[14] S.-M. W. K.-H. Chang, ”An LED Driver with Active EMI Mitigation Scheme," Electron Devices and Solid State Circuit (EDSSC), 2012, pp. 1-4.

[15] M. Arias, D. G. Lamar, F. F. Linera, D. Balocco, A. A. Diallo, Sebastia, et al., "Design of a Soft-Switching Asymmetrical Half-Bridge Converter as Second Stage of an LED Driver for Street Lighting Application," Power Electronics, IEEE Transactions, vol. 27, pp. 1608-1621, 2012.

[16] M. R. Cosetin, T. E. Bolzan, P. C. V. Luz, M. F. da Silva, J. M. Alonso, and R. N. do Prado, ”Dimmable singlestage SEPIC-Cuk converter for LED lighting with reduced storage capacitor," Industry Applications Society Annual Meeting, 2014 IEEE, 2014, pp. 1-7.

[17] Y.-z. Xu, W.-m. Lin, Y.-c. Xu, and Y.-j. Shao, "Inductor Optimize Design for BCM BUCK-PFC in LED Driver," Electric Information and Control Engineering (ICEICE), 2011 International Conference, 2011, pp. 2264-2267.

[18] M. R. Cosetin, P. C. V. Luz, M. F. da Silva, F. Bisogno, J. M. Alonso, and R. N. do Prado, "Long-Lifetime SEPIC-Buck Integrated Converter for LED Lighting Application,'Industry Applications (INDUSCON), 2012 10th IEEE/IAS International Conference, 2012, pp. 1-7.

[19] M. R. Cosetin, P. C. V. Luz, E. A. Bitencourt, M. F. da Silva, F. Bisogno, J. M. Alonso, et al., "Off-Line SingleStage SEPIC-Buck Converter for Dimmable LED Lighting with Reduced Storage Capacitor,'Power Electronics and Applications (EPE), 2013 15th European Conference, 2013, pp. 1-10.

[20] L. Ray-Lee, L. Chia-Chun, and C. Yi-Chun, "Optimal Design of LED Array for Single-Loop CCM Buck-Boost LED Driver," Industry Applications Society Annual Meeting (IAS), 2011 IEEE, 2011, pp. 1-5.

[21] H. Chin Yuan and C. Yu Liang, "A Single Stage Single Switch Valley Switching Flyback-Forward Converter with Regenerative Snubber And Pfc For LED Light Source System," Intelligent Green Building and Smart Grid (IGBSG), 2014 International Conference, 2014, pp. 1-6.

[22] Y. Liu and Y. Jinming, "The Topologies of White LED Lamps' Power Drivers,"Power Electronics Systems and Applications, 2009. PESA 2009. 3rd International Conference, 2009, pp. 1-6.

[23] W. A. Junying Niu ; Yuhong Song ; Zhong Li ; Halang, "Reducing EMI in Half-Bridge Resonant LED Drivers with Chaos-based PWM," Electromagnetic Compatibility (EMC EUROPE), 2013 International Symposium, 2013, pp. $637-640$

[24] K. O. Mainali, R. , "Conducted EMI Mitigation Techniques for Switch Mode Power Converters A Survey,"Power Electronics, IEEE Transactions, vol. 25, pp. 2344 - 23562010. 
[25] M. Kuisma, "Variable Frequency Switching in Power Supply EMI-Control: An Overview,"Aerospace and Electronic Systems Magazine, IEEE vol. 18, pp. 18-22, 2003.

[26] K. Junsik, L. Jiyong, and P. Shihong, ”A Soft Self-Commutating Method using Minimum Control Circuitry for Multiple-String LED Drivers," Solid-State Circuits Conference Digest of Technical Papers (ISSCC), 2013 IEEE International, 2013, pp. 376-377.

[27] W. A. Venturini, E. A. Bitencourt, M. E. Schlittler, M. F. da Silva, R. N. do Prado, and F. E. Bisogno, ”Analysis and Design Methodology of A Self-Oscillating System Based on Integrated Sepic Half-Bridge for LED Lightning Applications," Power Electronics Conference (COBEP), 2013 Brazilian, 2013, pp. 1120-1127.

[28] M. R. Cosetin, P. C. V. Luz, M. F. da Silva, F. Bisogno, J. M. Alonso, and R. N. do Prado, "Single-Stage SepicBuck Converter for LED Lighting wth Reduced Storage Capacitor,'IECON 2012 - 38th Annual Conference on IEEE Industrial Electronics Society, 2012, pp. 4597-4603.

[29] Y. Yang, R. Xinbo, Z. Li, H. Jiexiu, and Y. Zhihong, "A Feed-Forward Scheme for an Electrolytic CapacitorLess AC/DC LED Driver to Reduce Output Current Ripple,'Power Electronics, IEEE Transactions, vol. 29, pp. 5508-5517, 2014.

[30] A. K. R. Rasheed;, ”Double Stage Buck Boost Converter For LED Lighting Application,'International Conf. on Electrical, Electronics, Mechanical \& Computer Engineering, Cochin, India, 2014, pp. 22-29.

[31] G. C. Pasetti, N. ; Tinfena, F. ; Serventi, R. ; D’Abramo, P. ; Saponara, S. ; Fanucci, L. , ”Characterization of An Intelligent Power Switch for LED Driving with Control of Wiring Parasitics Effects," Design, Automation \& Test in Europe Conference \& Exhibition (DATE), 2011, pp. 1 - 2.

[32] M. Merhy, C. Morel, E. Chauveau, M. Machmoum, and C. Morel, Reducing the Spectral Emissions of PFC Converters by Anticontrol of Chaos, Int. J. Power Electron. Drive Syst., vol. 3, no. 2, pp. 129146, 2013.

[33] L. Keon, L. Dong-Hun, Y. Su-hun, P. Ji-Hyun, and Y. Kwang-Sub, ”Design of High Dimming Ratio Power-LED Driver with Preloading Inductor Current Methodology," in SoC Design Conference (ISOCC), 2012 International, 2012, pp. 9-12.

[34] G. M. Soares, P. S. Almeida, D. P. Pinto, and H. A. C. Braga, ”A Single-Stage High Efficiency Long-Life Off-Line LED Driver Based on The DCM Cuk Converter,"in IECON 2012 - 38th Annual Conference on IEEE Industrial Electronics Society, 2012, pp. 4509-4514.

[35] D. Nielsen, M. A. E. Andersen, and K. S. Meyer, "Preliminary Investigations of Piezoelectric Based LED Luminary," in Power Electronics and Applications (EPE 2011), Proceedings of the 2011-14th European Conference, 2011, pp. 1-9.

[36] C. Jettanasen; and C. Pothisarn;, "Analytical Study of Harmonics Issued from LED Lamp Driver,"in Proceedings of the International Multi Conference of Engineers and Computer Scientists, Hong Kong, 2014.

[37] L. Svilainis, "LED Brightness Control for Video Display Application,” Displays, vol. 29, pp. 506-511, 2008.

[38] J.-H. Ahn, 'Implementation Of An Led Tile Controller for High-Quality Image Display,” Displays, vol. 34, pp. 17-26, 2013.

[39] V. Mohan;, N. Stalin;, and S. Jeevananthan;, A Tactical Chaos based PWM Technique for Distortion Restraint and Power Spectrum Shaping in Induction Motor Drives, Int. J. Power Electron. Drive Syst., vol. 5, no. 3, pp. 383392, 2015.

[40] D. Gonzalez, J. Balcells, A. Santolaria, J. C. Le Bunetel, J. Gago, D. Magnon, et al., "Conducted EMI Reduction in Power Converters by Means of Periodic Switching Frequency Modulation," Power Electronics, IEEE Transactions, vol. 22, pp. 2271-2281, 2007.

\section{BIOGRAPHIES OF AUTHORS}

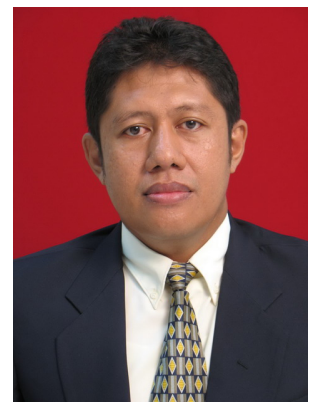

Mohammad Yanuar Hariyawan is a Lecturer at Electrical Department, Politeknik Caltex Riau, Pekanbaru, Indonesia. Currently, $\mathrm{He}$ is a PhD Student at the Department of Electrical Engineering and Information Technology, Gadjah Mada University, Yogyakarta 55281, Indonesia. He received his BsC in Telecommunication Multimedia in 2001 from Sepuluh Nopember Institute of Technology, Indonesia, M.T in 2008 from the Sepuluh Nopember Institute of Technology, Indonesia. His research interest includes Electromagnetic Compatibility, and RF Harvesting. 

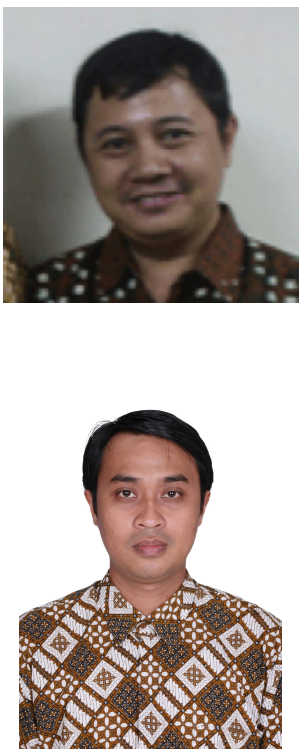

Risanuri Hidayat is a lecturer at the Department of Electrical Engineering and Information Technology, Gadjah Mada University, Yogyakarta 55281, Indonesia. He received his BSC in Electrical Engineering in 1992, M.Sc (Electrical Engineering) in 2002 from the Information and Communication Technology, Agder University College, Norway and PhD in 2009 at Telecommunication Engineering, King Mongkuts Institute of Technology Ladkrabang (KMITL), Bangkok, Thailand. His research interest includes Signal Processing, Digital and Analog Circuit Design, and telecommunication Systems, Data Communication and Networking, Java Programming and its Applications and Speech and Image Recognition.

Eka Firmansyah is a lecturer at the Department of Electrical Engineering and Information Technology, Gadjah Mada University, Yogyakarta 55281, Indonesia. He was born in Yogyakarta, Indonesia on March 3rd, 1979. He got his BSc in electrical engineering form UGM, Indonesia in 2001, M.Eng in Power Electronics from NTU, Singapore in 2005, and Ph.D. in Power Electronics from Kyushu University, Japan in 2010. His research interest is in PFC topology and inverter circuit for renewable energy and motor control. 